\title{
Bağımsız Denetim Görüşünün Hisse Senedi Getirileri Üzerine Etkisi: Borsa İstanbul Uygulaması ${ }^{1}$
}

\begin{abstract}
Bağımsız Denetim Görüşünün Hisse Senedi Getirileri Üzerine Etkisi: Borsa İstanbul Uygulaması

Öz

Bu çalışmanın amacı, bağımsız denetim görüşlerinin açıklandığı tarih ve etrafındaki günlerde, Borsa İstanbul pay piyasasında işlem gören hisse senetlerinden elde edilen getirilerde meydana gelen değişikliği araştırmaktır. Bu amaçla BIST-TÜM endeksinde 20092018 yılları arasında sürekli faaliyet gösteren ve üç ayda bir bağımsız denetim görüşü yayınlayan 17 firmanın toplamda 612 bağımsız denetim raporu incelenmiştir. Çalışmada Olay Çalışması (Event Study) Yöntemi, Patell Testi (Patell Z-Statistic) ve Standardize Edilmiş Çapraz Kesit Testi (Standardized Cross-Sectional Test) uygulanmıştır. Test sonuçlarından elde edilen bulgulara göre $(-10,+10)$ olay aralığında bağımsız denetim görüşleri hisse senedi getirileri üzerinde istatistiksel olarak anlamlı değildir. Bu sonuç, bağımsız denetim görüşlerinin, yatırımcıların alım-satım kararlarını etkilemediğini göstermektedir. Dolayısıyla, Borsa İstanbul (bu çalışmada kullanılan firmalar kısıtıyla) yarıgüçlü formda etkindir.
\end{abstract}

Anahtar Kelimeler: Borsa İstanbul, Bağımsız Denetim Görüşü, Hisse Senedi Anormal Getirileri, Olay Çalışması.
The Effects of Independent Audit Opinion on Stock Returns: Case of Borsa İstanbul

Abstract

The purpose of this study is to investigate the change in the stock returns traded on the Borsa istanbul shares market in the days surrounding the announcement of the independent audit opinions and the days around. For this purpose, 612 independent audit reports of 17 firms, which have been operating continuously in BISTTÜM index between 2009 and 2018 and published quarterly independent audit opinions, were examined. In the study, Event Study Method, Patell Z-Statistic and Standardized Cross-Sectional Test were applied. According to the results obtained from the test results ($10,+10)$ in the event interval, independent audit opinions are not statistically significant on stock returns. This result shows that independent audit opinions do not affect investors' trading decisions. Therefore, Borsa İstanbul (limited by the firms used in this study) is effective in a semi-strong form.

Keywords: Borsa İstanbul, Independent Audit Opinion, Stock Abnormal Returns, Event Study.

\section{Giriş}

Muhasebe, finansal özellikli işlemleri kaydeder, sınıflandırır ve finansal tablolar halinde bilgi kullanıcılarına sunar. Muhasebe kayıtlarının son aşaması ise raporlamadır. Raporlamanın şeffaf ve doğru yapılması; yatırım sahipleri, kredi sağlayıcılar, yöneticiler ve düzenleyici kuruluşlar için önemlidir.

2013 yılında yeni Türk Ticaret Kanunu (TTK)'nın uygulanmaya başlanmasıyla ülkemizde faaliyet gösteren işletmelerin vergi amaçlı mali tablo düzenlemenin dışında uluslararası muhasebe standartları ve finansal raporlama standartları çerçevesinde mali işlem ve uygulamaları kaydetme ve raporlama gerekliliği doğmuştur (Ayanoğlu ve Yılmaz, 2016:43).

${ }^{1}$ Bu çalışma, Gaziantep Üniversitesi Sosyal Bilimler Enstitüsü Işletme Anabilim Dalı’nda, Dr. Öğr. Üyesi Ş. Gül Reis danışmanlığında, Kenan Sağım tarafından "Bağımsız Denetim Görüşünün Hisse Senedi Getirileri Üzerine Etkisi: Borsa İstanbul Uygulaması" ismiyle tamamlanarak 30.11.2018 tarihinde savunulan yüksek lisans tezinden türetilmiş ve "Internatıonal Congress Of Management Economy And Polıcy 2018 Autumn" kongresinde bildiri olarak sunulmuştur.

${ }^{2}$ Gaziantep Üniversitesi, SBE, İşletme Ana Bilim Dalı. kenansagim@hotmail.com, Yazar ORCID bilgisi: https://orcid.org/0000-00018143-8837

${ }^{3}$ Dr. Öğr. Üyesi, Gaziantep Üniversitesi, IiBBF, İşletme Bölümü. greis@gantep.edu.tr, Yazar ORCID bilgisi: https://orcid.org/0000-00017654-4256 
Sermaye Piyasası Kurulu (SPK) “Finansal Raporlama Standartları'nın Uluslararası Standartlara Tam Uyum Projesi"ni hayata geçirmiş, bu çerçevede Uluslararası Finansal Raporlama Standartları (UFRS) ile uyumlu muhasebe standartları olan Türkiye Muhasebe Standartları (TMS) ve Türkiye Finansal Raporlama Standartları (TFRS)' nin Türkiye'de uygulanması zorunlu hale gelmiştir. Bu standartlar sadece SPK tarafından belirtilen ölçütleri aşan şirketler tarafından uygulanmıştır. Bundan dolayı bağımsız denetim bu süreçte kamu ve özel sektör açısından bağımsız ve güvenilir bilgi sunmada önemli rol oynamaktadır (Erol ve Aslan, 2017:65).

Bağımsız denetim uygulaması 1987 yııında Türkiye'de bankacılık sektörü ile başlamıştır. SPK 13.12.1987 tarihli ve 19663 sayılı Resmi Gazete' de yayımlanan "Sermaye Piyasasında Bağımsız Dış Denetleme Hakkındaki Yönetmelik" ile yürürlüğe girmiştir (Resmi Gazete, 1987). 1989 yılında halka açık şirketler denetim kapsamına alınmıştır. "Sermaye Piyasasında Bağımsız Dış Denetleme Hakkındaki Yönetmelik" 28.05.2013 tarihli ve 28660 sayılı Resmi Gazete' de yayımlanan karar ile yürürlükten kaldııılmıştır (Resmi Gazete, 2013). Türkiye'de SPK, Ekim 2018 tarihinden itibaren 265 şirketi bağımsız denetim yapmak için yetkilendirmiştir (Kamu Gözetimi Muhasebe ve Denetim Standartları Kurumu, 2018).

Genel olarak bağımsız denetim, işletme ile ilişiği bulunmayan kişi veya kurumlarca denetlenen işletme hakkında yöneticilere veya finansal tablo kullanıcılarına bilgi verilmesidir. Denetçi araştırma ve değerlendirmeleri sonucu işletme hakkında genel bir rapor hazırlayarak sunmaktadır. Sadece mali kayıtların kontrolü dar anlamda bağımsız denetimi ifade etmektedir. Mali belge ve kayıtların incelenerek işletmenin mali tabloları hakkında rapor hazırlanarak sunulmaktadır (Kepekçi, 2000:1; Ulusoy, 2007:38).

Bağımsız denetimde, finansal tabloların değerlendirmesi yapılarak denetim raporu aracılığıyla elde edilen sonuçlar kamuoyu ile paylaşılmaktadır. Denetim sonrası denetçi, ulaştığı sonuçları kamuoyuna açıklarken dört farklı görüş bildirmektedir. Bu görüş türleri; olumlu görüş, olumsuz görüş, şartlı görüş ve görüş bildirmekten kaçınmadır. Denetim sonrası kamuoyuna açıklanan denetim raporları ve görüşleri yatırımcıların kararlarını etkileyebilmektedir. Çünkü bu raporlar firmalar hakkında yatırımcılara bir bilgi sunmaktadır. Yatırımcılar elde edilen bu bilgilerle varlıklarını yeniden değerlendirebilmektedirler. Diğer faktörlerin yanında yatırımcıların karar verme sürecine etki eden denetim raporlarından ve görüşlerinden elde edinilen bilgiler, yatırımcılar için önemli bir bilgi kaynağı olmaktadır.

Yatırımcıların yatırım kararlarını etkileyen birçok faktör bulunmaktadır. Bu faktörler, finansal tablo kalemlerinden elde edilen oranlar, geçmiş fiyat verileri ve firmaya ilişkin kamuya açıklanan ya da açıklanmayan bilgiler şeklinde ortaya çıkmaktadır. Fama(1970) yapmış olduğu çalışmada, ulaşılabilir tüm bilgilerin hisse senedi fiyatlarına tamamen yansıdığına ilişkin açıklamaları içeren Etkin Piyasa Hipotezi'ni ifade ederken üç tip etkinlik formundan bahsetmiştir. Bunlardan birincisi zayıf formda etkinliktir ki bu form geçmiş fiyat verilerinden ekstra bir getiri elde edilemeyeceğini savunur. İkincisi, yarı-güçlü formda etkinlik olarak adlandırılır ve hem geçmiş fiyatlardan hem de halka açıklanan bilgilerden ekstra bir getiri elde edilemeyeceğini ifade eder. Üçüncüsü ise, güçlü formda etkinliktir. Güçlü formda etkinliğe göre, geçmiş fiyatlardan, halka açıklanan ve açıklanmayan bilgilerden ve halka açıklanmayan ekstra bir kazanç elde edilemeyeceğini savunur.

Bu çalışmada, Borsa İstanbul' da faaliyet gösteren firmaların açıkladığı bağımsız denetim görüşlerinin hisse senedi yatırımcılarına ekstra kazanç sağlama noktasında bir etkisinin olup olmadığı araştırı mıştır. Bunun için $(+10,-10)$ olay aralığı seçilerek hazırlanan getiri verilerinden bağımsız denetim görüşünün açıklandığı gün ve etrafındaki günlerde hisse senedi getirilerine 
etkisi Olay Çalışması yöntemiyle test edilmiştir. Sonuçlar Borsa İstanbul' da $(-10,+10)$ olay aralığında piyasanın yarı-güçlü formda etkin olduğunu göstermiştir.

\section{Literatür Araştırması}

Denetim raporları karar alma sürecinde yatırımcılara faydalı bilgiler sunabilmektedir. Türkiye'de yapılan çalışmalar incelendiğinde, bağımsız denetim görüşlerinin hisse senedi getirilerine etkisi üzerine yapılmış sınırlı sayıda çalışma bulunduğu görülmüştür. Çalışmanın bu bölümünde, bağımsız denetim görüşlerinin hisse senedi getirileri üzerinde yatırımcıların karar alma sürecine etkisinin olup olmadığına ilişkin bir literatür incelemesi yapılmış ve özetlenmiştir.

Firth (1978) çalışmasında, nitelikli denetim raporlarının, hisse senedi fiyatları ve yatırımcı kararları üzerindeki etkisini araştırmıştır. Belirli türdeki denetim raporlarının, portföy sahiplerinin portföy kararlarında kullandıkları önemli bilgiler içerdiğini tespit etmiştir. Aynı zamanda yatırımcıların diğer denetim görüşlerine de farklı şekilde tepki verdiklerini çalışmasında dile getirmiştir. Olay penceresi olarak, $(-20,+20)$ aralığı belirlenmiştir. Araştırma kapsamına Birleşik Krallık' ta işlem gören 247 şirketin 1974 ve 1975 yıllarındaki nitelikli denetim görüşleri dâhil edilmiştir. Araştırmada ortalama anormal ve kümülatif anormal getiriler hesaplanmıştır. Şartlı denetim görüşlerinin hisse senedi fiyatlarına tepki verdiğini tespit etmiştir. Denetim görüşlerinin yatırımcı kararlarını etkilediği sonucuna varmıştır.

Ameen vd. (1994) çalışmalarında, nitelikli denetim görüşlerinin hisse senedi anormal getirileri üzerine etkisini araştırmışlardır. ABD’de tezgâh üstü piyasada listelenen 177 firmanın 1974-1978 yılları arasındaki denetim görüşleri dikkate alınmıştır. Araştırmalarında olay penceresi olarak $(-1,+1)$ ve $(-2,+2)$ olay aralığı belirlenmiştir. Araştırmada ortalama ve kümülatif anormal getiriler hesaplanmıştır. Nitelikli denetim görüşlerinin hisse senedi getirileri üzerinde önemli bir etkisinin olmadığı sonucuna ulaşılmıştır.

Fleak ve Wilson (1994) denetçi değerlendirmelerinin hisse senedi fiyatlarını etkileyip etkilemediğini araştırmışlardır. Ulusal Muhasebe Araştırma Sistemi (NAARS)'da listelenen 478 firmanın 1979-1986 yılları arasındaki denetçi görüşleri dikkate alınmıştır. Araştırmalarında olay penceresi olarak $(-1,+1),(-3,+3)$ ve $(-5,+5)$ olay aralığı belirlenmiştir. Denetçi görüşlerinin hisse senedi fiyatlarını etkileyecek yeni bilgiler sağladığı hipotezi kabul edilmiştir.

Denetçi raporunun yayınlanmasından önce hisse senedi fiyatlarındaki değişiklikleri araştıran Chen ve Church (1996), piyasanın iflas davalarına verdiği tepkinin açıklanmasında, denetim görüşlerinin faydalı olduğunu savunmuşlardır. Denetçi raporunun yayınlanmasından önce hisse senedi fiyatlarındaki değişimlere tepkisinin ardından, hisse senetlerindeki beklenmedik düşüşün firmalar için daha az olumsuz olduğu görülmüştür. Çin Borsası'nda işlem gören 106 iflas firması denetim raporlarının türüne göre, iflas başvurusundan hemen önce sınıflandırılmıştır. Olay penceresi $(-10,+10)$ olay aralığı olarak belirlenmiş ve T-Testi uygulanmıştır. Denetim görüşleri ile iflas davalarına tepkisi araştırılırken, iflas olasılığı gibi diğer değişkenleri kontrol ettikten sonra, piyasanın iflas etmeden önce finansal sıkıntılarının ifşa edilmesine verdiği tepki ve denetim raporunun yayınlanmasından önce hisse senedi fiyatlarındaki değişiklikler, denetim görüşlerinin faydalı olduğu sonucuna ulaşılmıştır.

Chen vd. (2000), Çin Şangay Menkul Kıymetler Borsası'nda işlem gören 1995-1997 yılları arasındaki 844 firmanın değiştirilmiş denetim görüşlerine piyasa tepkisini ölçmek istemişlerdir. Olumlu ve şartlı denetim görüşlerinin hisse senedi fiyatları üzerine etkisini incelemiştir. Olay penceresi $(-15,+15)$ olay aralığı olarak belirlenmiştir. Olumlu ve şartlı denetim görüşleri sonrası hisse senedi üzerinde anormal getiriler elde edildiği sonucuna ulaşılmıştır. 
Martinez vd. (2004), çalışmalarında İspanyol Sermaye Piyasası'nda denetim raporlarının hisse senedi fiyatları ile ilişkisi olup olmadığını incelemiştir. İncelemede olay çalışması metodolojisi kullanılmıştır. Olay penceresi $(-12,+12)$ olay aralığı olarak belirlenmiştir. Denetim raporlarının, yararlanıcılar için önemli bir bilgi değerinin olmadığını ileri sürmüşlerdir.

Aygören ve Uyar (2007) çalışmalarında, denetim görüşlerinin iMKB'de işlem gören hisse senetleri üzerindeki etkisini araştırmışlardır. Araştırmada, IMKB'de bulunan 101 şirketin 2004 ve 2005 yılları denetim raporlarındaki görüşleri ele alınmıştır. Veri değerlendirilmesinde olay çalışması yöntemi kullanıımış ve piyasanın yarı kuvvetli etkin olduğunu varsaymıştır. Bu çalışmada inceleme konusu olan olay "denetim raporunun açıklanması", olayın gerçekleşmesi ise denetim raporunun açıklandığı gün olarak belirtilmiştir. Olay penceresinin uzun seçilmesi çalışmanın istatistiksel olarak gücünü azaltabilmekte, olay penceresinin kısa seçilmesi çalışmanın etkilerini net olarak gösterebilmektedir. Bu nedenle bu çalışmada olay penceresi uzunluğu $(-10,+10)$ seçilmiştir. Olumlu denetim görüşü hisse senedi getirisi üzerinde negatif etki oluştururken, şartlı denetim görüşünün ise hisse senedi üzerinde negatif ve pozitif anormal getirileri olduğu sonucuna ulaşıımıştır.

Al-Thuneibat vd. (2008), nitelikli denetim raporlarının Ürdün'de hisse senedi fiyatları ve getirileri üzerindeki etkisini araştırmıştır. 2000-2005 yılları arasındaki nitelikli denetim raporlarını incelemişlerdir. Olay penceresi $(-7,+7)$ olay aralığı olarak belirlenmiştir. Araştırmada aynı zamanda T-Testi kullanılmıştır. Nitelikli bir denetim görüşünün hisse senedi fiyatları ve getirileri üzerinde açık ve önemli bir etkisinin olmadığı sonucuna ulaşılmıştır.

Tahinakis vd. (2010), çalışmalarında Atina Menkul Kıymetler Borsası'nda işlem gören şirketlerden 2005-2007 yılları arasındaki nihai olarak 39 şirkete karşılık gelen 51 denetim raporunu ele almıştır. Olay penceresi $(-5,+5)$ olay aralığı olarak belirlenmiştir. Pazar araştırması modeli, araştırmanın metodolojisi olarak kullanılmıştır. Denetim raporlarının karar alıp verme sürecinin bir parçası olmadığı ve yararlanıcılar için sınırlı bilgi sağladığı anlaşımıştır. Bu tür raporların önemi ve değerinin anlaşılmadığı görülmüştür.

Moradi vd. (2011), çalışmalarında denetim raporunu, denetçi ile finansal tabloların yararlanıcıları arasındaki bilgi akışını sağlayan bir araç ve denetim sürecinin sonucu olarak görmüştür. Denetim raporunu test etmek için denetim raporları ile hisse senedi fiyatları arasındaki ilişkiyi incelemiştir. Olay penceresi $(-5,+5)$ olay aralığı olarak belirlenmiştir. Incelemede T-Testi uygulanmıştır. 2005-2009 yılları arasında İran'da gerçekleştirilen bu inceleme sonucunda denetim görüşlerinin yararlanıcılar tarafından anlaşılmadığı ve değerli bir bilgi olarak görülmediği sonucuna ulaşılmıştır.

Anvarkhatibi vd. (2012), çalışmalarında denetim görüşlerinin Tahran Menkul Kıymetler Borsası'nda hisse senedi fiyatları üzerine etkisini araştırmıştır. 2002-2008 yılları arası Tahran Menkul Kıymetler Borsası'ndaki şirketler incelemeye alınmıştır. İncelemede Mann-Whitney U Testi uygulanmıştır. Araştırmalarında olay pencereleri $(-100,+100),(-30,+30),(-15,+15)$ ve $(-7$, $+7)$ olay aralığı olarak belirlenmiştir. Inceleme sonucunda, Tahran Menkul Kıymetler Borsası'ndaki denetçi görüşünün hisse fiyatları ve getirileri üzerine etkisi olmadığı sonucuna ulaşılmıştır.

Hoti vd. (2012), Slovenya ve Hırvatistan'da kamu yararı için faaliyet gösteren işletmelerin, denetim sonrası finansal yılsonu raporlarının açıklanmasından sonra, hisse senedi fiyatları üzerindeki etkilerini araştırmışlardır. Araştırmada 2007 yılında 275 şirketin nitelikli denetim raporları incelenmiştir. Araştırmada hisse senedi fiyat dalgalanmalarının tepkilerini ve değişkenlerin denetimle ilgisi incelenmiştir. Bu incelemede diskriminant analizi ve logit 
modelleri uygulanmıştır. Araştırma sonucunda denetçi görüşünün ve denetim kalitesinin hisse senedi getirileri üzerinde etkili olduğu görülmüştür.

Kara (2015), çalışmasında denetim görüşlerinin BIST' de işlem gören hisse senetleri üzerindeki etkisini araştırmıştır. Araştırmada BIST' de işlem gören 88 şirketin 2009-2014 yılları arası denetim raporlarındaki görüşleri ele alınmıştır. Analizde yer alan şirketlerin hisse senetleri fiyatları, finansal tablolarını ilan ettikleri tarihi olay anı olarak kabul etmiş ve her şirketin açıklanan denetim görüşlerinin bu tarihe göre beş gün öncesi ve beş gün sonrası $(-5,+5)$ olay aralığı olarak belirlenmiştir. Veriler regresyon ve hipotez testleri yöntemlerine göre değerlendirilmiştir. Denetim raporlarının ilanı sonrasında hisse senedi ortalama anormal getirisi üzerinde pozitif yönlü, görüş bildirmekten kaçınma ve şartlı görüş bildirimleri hisse senedi ortalama anormal getirisi üzerinde ise negatif yönlü olduğu sonucuna ulaşmıştır. Denetim görüşü bildirimlerinin hisse senedi getirisine katkı sağladığını tespit etmiştir. Bu sonuç piyasanın yarı güçlü formda bile etkin olmadığını göstermiştir.

Wickramasingha ve Nanayakkara (2015) çalışmalarında, Sri Lanka Kolombiya Borsası'nda 2008-2013 yılları arasında imalat sektöründe faaliyet gösteren 31 şirket için açıklanan denetim görüşleri ve bu denetim görüşlerinin yatırımcıların karar alma sürecine etkisi incelenmiştir. Bu incelemede ANOVA yöntemi uygulanmıştır. İnceleme sonucunda yatırımcıların karar alma sürecinde denetim görüşlerinin bilgilendirici bir değer taşımadığı kanısına varılmıştır.

Bozkurt vd. (2015), çalışmalarında 2009-2011 yılları arasındaki yıllık yayınlanan finansal tabloların hisse senedi getirileri üzerindeki etkisini araştırmışlardır. BIST-100 endeksinde yer alan 167 firmanın finansal tablolarının açıklandığı gün öncesi ve sonrası beş borsa işlem gününü $(-5,+5)$ veri olarak kullanmıştır. Veriler olay çalışması yöntemi esas alınarak incelenmiştir. Inceleme sonucu finansal tabloların açıklanmasından önceki ve sonraki günlerde yatırımcıların anormal getiriler elde ettiği görülmüştür. Elde edilen sonuç, anormal getirilerin, firmaların yatırılan sermaye değerlerine göre değişiklik gösterdiğini ortaya koymuştur.

Ercan ve İşseveroğlu (2016), çalışmalarında olumlu denetim görüşünün 2013 ve 2014 yıllarında BIST 100'de işlem gören 92 şirketin hisse senetleri üzerindeki etkisi incelenmiştir. Denetim raporunun açıklandığı tarihten on gün öncesi ve on gün sonrasındaki $(-10,+10)$ hisse senedi fiyatlarının ortalaması veri olarak kullanılmıştır. Incelemede T-Testi uygulanmıştır. İnceleme sonucunda olumlu denetim görüşlerinin hisse senedi fiyatlarına etkisi olmadığı anlaşıımıştır. Denetim raporlarının önemi ve içeriğinin bilgi kullanıcıları tarafından yeterince bilinmemesi neden olarak görülmüştür.

Vaziri ve Azadi (2017), çalışmalarında Tahran Menkul Kıymetler Borsası'nda 2009-2014 yılları arasında işlem gören 117 şirketin denetim raporlarının finansal bilgiler üzerindeki ilişkisini araştırmışlardır. Bu araştırmada doğrusal regresyon modeli kullanılmıştır. Şirketler tarafından açıklanan bu finansal bilgilere etki eden faktörlerden biri de denetim raporlarıdır. Araştırma sonucuna göre denetim raporlarının hisse senedi getirisi ile önemli bir ilişkisi bulunduğu ortaya çıkmıştır.

\section{Uygulama}

\section{1. Çalışmanın Amacı ve Önemi}

Yatırımcılar hisse senedi alım-satım kararı alırken bir takım kriterleri değerlendirmektedir. $\mathrm{Bu}$ kriterler çoğunlukla geçmiş fiyat verileri, finansal tablolardan elde edilecek rasyolar ve firmaya ilişkin haberler olmaktadır. Bağımsız denetim görüşleri, firmanın finansal tablolarının hazırlanması ve raporlanması ile ilgili önemli bir değerlendirme olması nedeniyle yatırımcıların yatırım kararlarına etki edebilecek bir kriter olma özelliği taşımaktadır. 
Yatırım kararlarına etki eden kriterlerden biri olduğu düşünülen bağımsız denetim görüşlerinin, hisse senedi getirilerine olan etkisi bu araştırmanın amacını oluşturmaktadır. Bu amaçla, BiST' de denetim görüşü açıklanma tarihi etrafındaki günlerde(t+10, t, t-10) yatırımcıların elde ettikleri getiride meydana gelen değişiklik test edilmiştir.

\section{2. Çalışmanın Hipotezleri}

Bağımsız denetim görüşünün açıklandığı tarihin öncesinde ve sonrasında $(-10,+10$ olay aralığında) hisse senedi getirilerinde bir değişiklik olup olmadığı dolayısıyla hisse senedi getirilerinin istatistiksel olarak anlamlı bir şekilde etkilenip etkilenmediğine ilişkin araştırma problemi aşağıdaki hipotezler yardımıyla test edilmiştir.

$\mathrm{H}_{1}$ : Bağımsız denetim görüşünün hisse senedi getirileri üzerinde etkisi vardır.

$\mathrm{H}_{1 a} \quad$ : Olumlu bağımsız denetim görüşünün hisse senedi getirileri üzerinde pozitif bir etkisi vardır.

$\mathrm{H}_{1 b} \quad$ : Şartlı bağımsız denetim görüşünün hisse senedi getirileri üzerinde negatif bir etkisi vardır.

\section{3. Çalışmanın Kısıtları}

BIST' de 2018 yılı itibariyle faaliyet gösteren tüm borsa endekslerindeki toplam 513 şirketten sadece BIST-TÜM endeksinde yer alan şirketler tercih edilmiştir. BIST-TÜM endeksinde 2018 yılı itibariyle faaliyet gösteren 328 şirketten 2009-2018 yılları arası sürekli faaliyet gösteren 234 şirket belirlenmiştir. Sürekli faaliyet gösteren 234 şirket içerisinden sadece üç ayda bir bağımsız denetim görüşü yayınlanan 17 şirket belirlenmiştir. Üç ayda bir bağımsız denetim görüşü yayınlayan şirketlerin seçilmesi örneklemi küçültmesi araştırmanın kısıtı olmuştur.

\section{4. Çalışmada Kullanılan Veriler ve Değişkenler}

Çalışmada, BIST-TÜM endeksinde yer alan, 2009-2. döneminden 2018-1. dönemi sonuna kadar olan dönemde sürekli faaliyet gösteren 234 firma içerisinden üç ayda bir bağımsız denetim raporu yayınlayan 18 firmanın verileri araştırmanın kapsamına alınmıştır. Bu 18 şirketin üç ayda bir bağımsız denetim görüşleri listelendikten sonra, BIST günlük bültenlerden bağımsız denetim görüşü öncesi ve sonrası olmak üzere hisse senetleri fiyatları listelendiğinde 2015 yılı sonrası Türkiye Ekonomi Bankası'nın BIST'den çekildiği görülmektedir. Bu nedenle 17 şirkete ait 612 denetim görüşü kullanıımıştır. Bu belirlenen şirketlerin 11'ini bankacılık sektörü, 1 'ini gayrimenkul yatırım ortaklığı ve 5 'ini de imalat sektörü oluşturmaktadır.

Bağımsız denetim görüşü verileri Kamu Aydınlatma Platformu (KAP) resmi internet sitesinden elde edilmiştir. Hisse senedi getirileri hesaplanırken kullanılan hisse senedi gün sonu kapanış fiyatları ise, Borsa İstanbul (BIST) günlük bültenlerinden alınmıştır. BIST günlük bültenler aylık paketler halinde BIST kütüphanesinden temin edilmiştir. Her bir denetim görüşünün 10 gün öncesi, olay günü ve 10 gün sonrası toplamda 21 günlük hisse senedi kapanış fiyatları derlenerek çalışma verisi oluşturulmuştur.

Ryngaert ve Netter (1990) ve Mackinlay (1997), olay penceresinin uzun seçilmesinin çalışmanın gücünü istatistiksel olarak azaltabileceğini ve olayın anlamlılığını da yanlış değerlendirilmesine neden olabileceğini belirtmektedir. Illeri sürdükleri görüşe göre, olay penceresinin kısa seçilmesi olayın etkilerini net olarak yansıtmaktadır. Bu nedenle çalışmamızda olay penceresi uzunluğu $(-10,+10)$ olarak seçilmiştir.

\section{5. Çalışmanın Yöntemi}

Yatırımcılar hisse senedi getirilerini etkileyen değişkenleri sürekli merak etmişlerdir. Çünkü yatırım yaptıkları hisse senetlerindeki kazançlarını bu değişkenler etkilemektedir. Bu çalışma kapsamında bağımsız denetim görüşlerinin hisse senedi getirisine etkisi olup olmadığı 
incelenmiştir. Bu etki, Olay Çalışması (Event Study) Yöntemi, Patell Z-Statistic ve Standardized Cross-Sectional Test (StdCsect) testleri uygulanmak suretiyle araştırılmıştır. Gözlem sayısı ( $n>100$ ) büyüklüğü nedeniyle Patell-Z testinin kullanılması tercih edilmiştir.

\subsubsection{Olay Çalışması (Event Study) Yöntemi}

Olay çalışması yöntemi, incelemeye konu olan belirli bir olay aralığında hisse senedi fiyatları üzerindeki etkisini ölçmeyi sağlayan ve piyasaların olaylara verilen anormal tepkilerini ölçmekte kullanılan ekonometrik bir yöntemdir.

Olay çalışması yöntemi, hisse senedi fiyatlarını etkileyebilecek bir olayı ölçümlemek için geliştirilmiştir. Olay çalışması yöntemini uygulayabilmek için sadece hisse senedi fiyatları, firma ismi ve olay tarihi bilgilerinin yeterli olması uygulamayı kolaylaştırmaktadır (McWilliams ve Siegel, 1997; Aygören ve Uyar, 2007).

Olay çalışması, belirli bir olay gününün (event day), borsa getirileri üzerindeki etkisini incelemek amacıyla literatürde sıklıkla kullanılan yöntemlerdendir. Bu yöntemde öncelikle, hisse senetlerine ait günlük getirilerin beklenen getirileri hesaplanmakta ve gerçekleşen getiri arasındaki farkları incelenmektedir. Farklı olay çalışması metodolojileri arasındaki temel fark beklenen getirilerin belirlenmesi aşamasında gerçekleşmektedir. En yaygın kullanılan yöntemlerin başında En Küçük Kareler (EKK- Ordinary Least Squares, OLS) yöntemi ile hesaplanan Piyasa Modeli (Market Model) ve Sabit Ortalama Getiriler (Constant Mean Returns) modelleri gelmektedir. Brown ve Warner (1980), daha karmaşık dizayna sahip modellerin araştırmacılara ek fayda sağlamadığını ve daha sade olan modelleri kullanmanın yararlı olacağını vurgulamışlardır. Bu bağlamda bu çalışmada da beklenen getirilerin hesaplanmasında sabit ortalama getiriler modeli kullanıımıştır.

Olay çalışması yönteminde olay zamanının ve olay penceresinin belirlenmesi önemlidir. Olay penceresinin uzun seçilmesi çalışmanın gücünü istatistiksel olarak azaltabildiği gibi, olayın anlamlıı̆ı̆ını da yanlış değerlendirilmesine neden olabilmektedir. Olay penceresinin kısa seçilmesi olayın etkilerini net olarak yansıtmaktadır (Ryngaert ve Netter, 1990; Mackinlay, 1997). Bu nedenle çalışmamızda, incelenmeye konu olan olay zamanını "bağımsız denetim görüşünün yayınlandığı gün”, olay penceresinin uzunluğunun ise $(-10,+10)$ olarak seçilmesi uygun görülmüştür. $(-10,+10)$ olay penceresi uzunluğu (Chen ve Church, 1996; Aygören ve Uyar, 2007; Ercan ve İsseveroğlu, 2016) tarafından uygulanmıştır.

Olayın olduğu tarihten önceki ve sonraki günlerde (AR) Anormal Getiri, (AAR) Ortalama Anormal Getiri, (CAR) Kümülatif Anormal Getiri ve (CAAR) Ortalama Kümülatif Anormal Getiri hesaplanmalıdır. Bu noktada AAR ve CAAR dört aşamalı bir çalışma ile hesaplanabilmektedir.

\subsubsection{Patell Z-Statistic Testi ve Standardize Kesitsel Test (StdCsect Z)}

iki aritmetik ortalama arasındaki farkın anlamlılığını test etmek için T-Testi, ANOVA, Patell$Z$ testi gibi parametrik testler kullanılmaktadır. Bu çalışmada AAR ve CAAR gibi aritmetik ortalamalar arasındaki farkın anlamlılığını test etmek için Patell-Z testi kullanılmıştır. Gözlem sayısı 100'den büyük olan çalışmalarda $(n>100)$ dağılım normale yaklaştığı için $Z$ testi kullanılmaktadır. Patell (1976), Dodd ve Warner (1983), Mikkelson ve Partch (1986) ve Kolari ve Pynnonen (2011) tarafından önerilen bu parametrik test, geri dönüşlerin güvenlik olayları boyunca bağımsız olduğunu varsaymaktadır.

Boehmer v.d. (1991) tarafından geliştirilen Standardize Kesitsel Test (StdCsect Z) olay çalışması sonuçlarının önem düzeyini tahmin etmek için uygulanan standart bir kesitsel testtir. Bir çaprazlama varyansı ayarlaması dâhil edilerek bir olay tarihinde olası bir varyans artışını telafi eden standart çapraz kesit testini seçer. Patell testinin bir uzantısını temsil etmektedir. 


\section{Bulgular}

Olumlu denetim görüşü bildirilen firmaların olay günü on gün öncesi (-10 ) ve on gün sonrası (+10) hisse senedi ortalama anormal getirileri Tablo 1'de raporlanmıştır.

Tablo 1: Olumlu Denetim Görüşü (AAR) Anormal Ortalama Getiriler $(-10,+10)$

\begin{tabular}{cccccccc}
\hline Olumlu & AAR & Pozitif Getiri SayıSI & Negatif Getiri Sayısı & Patell Z & Olasılık & StdCSect Z & Olasılık \\
\hline \hline AAR(-10) & -0.0019 & 200 & 247 & -1.6384 & 0.1042 & -1.6803 & 0.0972 \\
AAR(-9) & -0.0008 & 203 & 244 & -0.3718 & 0.3723 & -0.3525 & 0.3749 \\
AAR(-8) & -0.0004 & 206 & 241 & -0.9117 & 0.2633 & -0.8792 & 0.2711 \\
AAR(-7) & -0.0003 & 194 & 253 & 0.2064 & 0.3905 & 0.2044 & 0.3907 \\
AAR(-6) & -0.0002 & 198 & 249 & -1.1338 & 0.2098 & -1.0813 & 0.2223 \\
AAR(-5) & 0.0019 & 221 & 226 & 2.5524 & 0.0154 & 2.1031 & 0.0437 \\
AAR(-4) & -0.0021 & 204 & 243 & -1.6520 & 0.1019 & -1.7517 & 0.0860 \\
AAR(-3) & 0.0000 & 226 & 221 & 0.4416 & 0.3619 & 0.4112 & 0.3666 \\
AAR(-2) & 0.0001 & 218 & 229 & 1.0590 & 0.2277 & 1.1790 & 0.1991 \\
AAR(-1) & 0.0009 & 213 & 234 & 1.1697 & 0.2013 & 1.1190 & 0.2133 \\
AAR(0) & 0.0011 & 224 & 223 & 1.9121 & 0.0641 & 1.7718 & 0.0830 \\
AAR(1) & -0.0007 & 205 & 242 & -0.0105 & 0.3989 & -0.0075 & 0.3989 \\
AAR(2) & -0.0010 & 210 & 237 & -0.8986 & 0.2664 & -0.9168 & 0.2621 \\
AAR(3) & -0.0007 & 197 & 250 & -0.1217 & 0.3960 & -0.1107 & 0.3965 \\
AAR(4) & -0.0011 & 217 & 230 & -0.7373 & 0.3040 & -0.6932 & 0.3137 \\
AAR(5) & -0.0010 & 205 & 242 & -1.3060 & 0.1700 & -1.1715 & 0.2009 \\
AAR(6) & -0.0004 & 218 & 229 & 0.0582 & 0.3983 & 0.0554 & 0.3983 \\
AAR(7) & -0.0002 & 211 & 236 & -0.1737 & 0.3930 & -0.1553 & 0.3942 \\
AAR(8) & 0.0001 & 206 & 241 & -0.2092 & 0.3903 & -0.2155 & 0.3898 \\
AAR(9) & 0.0002 & 202 & 245 & 0.1440 & 0.3948 & 0.1387 & 0.3951 \\
AAR(10) & -0.0016 & 195 & 252 & -1.8618 & 0.0705 & -1.6647 & 0.0998 \\
\hline
\end{tabular}

Tablo 1'de olumlu denetim görüşü bildirilen firmaların hisse senetlerinin ortalama anormal getirilerinde $(T)$ olay günü, olay gününün $(T-5),(T-2),(T-1)$ gün öncesi ve olay gününün $(T+8)$, $(T+9)$ gün sonrası ortalama anormal getirilerinin pozitif olduğu görülmüştür. Olay günü sonrası ortalama anormal getirilerin negatif yönlü bir eğilime girdiği izlenmektedir. Olay gününün 5 gün öncesi (T-5)'de istatistiksel anlamda 0,05 anlamlılık seviyesine, olay günü $(T)$ ve olay gününün 10 gün sonrası $(T+10)$ 'de ise istatistiksel anlamda 0,10 anlamlılık seviyesine sahip olduğu görülmektedir.

Olumlu denetim görüşü bildirilen firmaların olay günü on gün öncesi (-10) ve on gün sonrası (+10) hisse senetleri ortalama anormal getirilerinin negatif ve pozitif yönlü dağılım grafiği Şekil 1 'de raporlanmıştır.

Şekil 1: Olumlu Denetim Görüşü (AAR) Anormal Ortalama Getiriler $(-10,+10)$

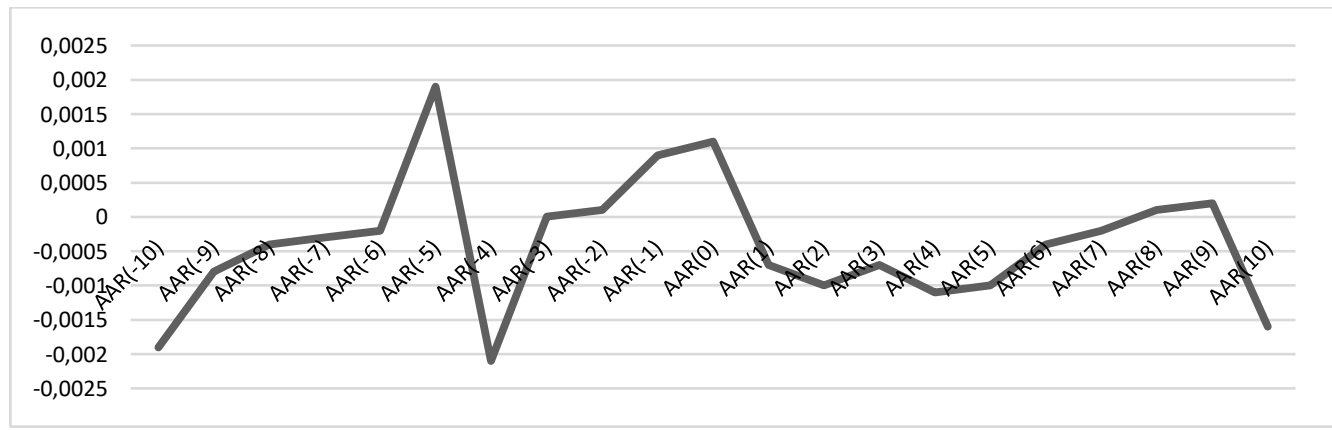

Şekil 1'de olumlu denetim görüşü bildirilen firmaların AAR $(-10,+10)$ olay aralığında hisse senetleri ortalama anormal getirilerinin negatif ve pozitif değerleri grafik üzerinde gösterilmiştir. Olumlu denetim görüşü bildirilen firmaların hisse senetlerinin ortalama 
anormal getirilerinde olay gününün (T-5) gün öncesi en yüksek pozitif ortalama anormal getiri elde ettiği görülmektedir. Olay gününün (T-4) gün öncesi ise en düşük negatif ortalama anormal getirileri elde ettiği görülmektedir.

Şartlı denetim görüşü bildirilen firmaların olay günü on gün öncesi (-10) ve on gün sonrası (+10) hisse senedi ortalama anormal getirileri Tablo 2'de raporlanmıştır.

Tablo 2: Şartı Denetim Görüşü (AAR) Anormal Ortalama Getiriler $(-10,+10)$

\begin{tabular}{cccccccc}
\hline 5 & AAR & Pozitif Getiri SayısI & Negatif Getiri SayısI & Patell Z & Olasılık & StdCSect Z & Olasılık \\
\hline \hline AAR(-10) & -0.0029 & 71 & 94 & -1.4890 & 0.1317 & -1.0407 & 0.2321 \\
AAR(-9) & 0.0010 & 80 & 85 & 1.3664 & 0.1569 & 0.9400 & 0.2565 \\
AAR(-8) & 0.0031 & 84 & 81 & 2.7536 & 0.0090 & 2.1637 & 0.0384 \\
AAR(-7) & 0.0003 & 94 & 71 & 0.2268 & 0.3888 & 0.1770 & 0.3927 \\
AAR(-6) & -0.0021 & 74 & 91 & -2.6199 & 0.0129 & -2.4004 & 0.0224 \\
AAR(-5) & 0.0040 & 92 & 73 & 2.6651 & 0.0114 & 2.2480 & 0.0319 \\
AAR(-4) & 0.0002 & 68 & 97 & -0.0477 & 0.3985 & -0.0496 & 0.3985 \\
AAR(-3) & -0.0015 & 73 & 92 & -1.5201 & 0.1256 & -1.2055 & 0.1929 \\
AAR(-2) & 0.0013 & 86 & 79 & 0.8140 & 0.2864 & 0.7683 & 0.2970 \\
AAR(-1) & -0.0022 & 77 & 88 & -0.9704 & 0.2491 & -1.0882 & 0.2207 \\
AAR(0) & -0.0011 & 81 & 84 & 0.1592 & 0.3939 & 0.1545 & 0.3942 \\
AAR(1) & -0.0029 & 84 & 81 & -0.9644 & 0.2506 & -0.8328 & 0.2820 \\
AAR(2) & -0.0044 & 78 & 87 & -1.1664 & 0.2021 & -1.0755 & 0.2237 \\
AAR(3) & 0.0008 & 81 & 84 & 1.0948 & 0.2191 & 1.0286 & 0.2351 \\
AAR(4) & 0.0005 & 86 & 79 & 0.0494 & 0.3985 & 0.0565 & 0.3983 \\
AAR(5) & -0.0015 & 76 & 89 & -0.1115 & 0.3965 & -0.1336 & 0.3954 \\
AAR(6) & -0.0003 & 85 & 80 & -0.2808 & 0.3835 & -0.2555 & 0.3861 \\
AAR(7) & -0.0016 & 71 & 94 & -1.2337 & 0.1864 & -1.3093 & 0.1693 \\
AAR(8) & 0.0006 & 87 & 78 & 0.8010 & 0.2895 & 0.8900 & 0.2685 \\
AAR(9) & 0.0008 & 83 & 82 & 0.6178 & 0.3296 & 0.6620 & 0.3204 \\
AAR(10) & -0.0010 & 77 & 88 & -1.2140 & 0.1909 & -1.2515 & 0.1823 \\
\hline
\end{tabular}

Tablo 2'de şartlı denetim görüşü bildirilen firmaların hisse senetlerinin ortalama anormal getirilerinde olay gününün (T-9), (T-8), (T-7), (T-5), (T-4), (T-2) gün öncesi ve olay gününün (T+3), $(T+4),(T+8),(T+9)$ gün sonrası ortalama anormal getirilerinin pozitif olduğu görülmüştür. $(-10$, $+10)$ olay aralığında diğer günlerin ortalama anormal getirilerin negatif olduğu görülmektedir. Olay gününün 8 gün öncesi (T-8), 6 gün öncesi (T-6) ve 5 gün öncesi (T-5)'de istatistiksel anlamda 0,05 anlamlılık seviyesine sahip olduğu görülmektedir.

Şartlı denetim görüşü bildirilen firmaların olay günü on gün öncesi (-10) ve on gün sonrası (+10) hisse senetleri ortalama anormal getirilerinin negatif ve pozitif yönlü dağılım grafiği Şekil 2 'de raporlanmıştır.

Şekil 2: Şartıı Denetim Görüşü (AAR) Anormal Ortalama Getiriler (-10, +10)

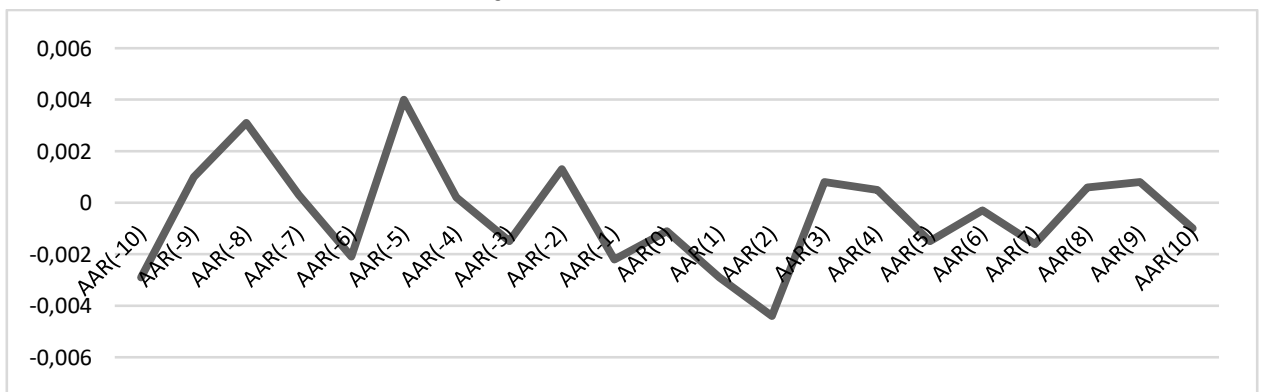

Şekil 2'de şartlı denetim görüşü bildirilen firmaların AAR $(-10,+10)$ olay aralığında hisse senetleri ortalama anormal getirilerinin negatif ve pozitif değerleri grafik üzerinde gösterilmiştir. Şartlı denetim görüşü bildirilen firmaların hisse senetlerinin ortalama anormal getirilerinde olay gününün (T-5) gün öncesi en yüksek pozitif ortalama anormal getiri elde ettiği 
görülmektedir. Olay gününün $(T+2)$ gün sonrası ise en düşük negatif ortalama anormal getirileri elde ettiği görülmektedir.

Olumlu ve Şartlı denetim görüşü bildirilen firmaların olay günü on gün öncesi (-10) ve on gün sonrası (+10) hisse senedi ortalama anormal getirilerinin tamamı Tablo 3'de raporlanmıştır.

Tablo 3: Olumlu ve Şartı Denetim Görüşü (AAR) Anormal Ortalama Getiriler $(-10,+10)$

\begin{tabular}{cccccccc}
\hline TamamI & AAR & Pozitif Getiri SayısI & Negatif Getiri Sayısı & Patell Z & Olasilık & StdCSect Z & Olasilık \\
\hline \hline AAR(-10) & -0.0022 & 271 & 341 & -2.1734 & 0.0376 & -1.9488 & 0.0597 \\
AAR(-9) & -0.0004 & 283 & 329 & 0.3917 & 0.3695 & 0.3331 & 0.3774 \\
AAR(-8) & 0.0005 & 290 & 322 & 0.6506 & 0.3228 & 0.5860 & 0.3360 \\
AAR(-7) & -0.0001 & 288 & 324 & 0.2941 & 0.3821 & 0.2702 & 0.3846 \\
AAR(-6) & -0.0007 & 272 & 340 & -2.3293 & 0.0265 & -2.1944 & 0.0359 \\
AAR(-5) & 0.0025 & 313 & 299 & 3.5652 & 0.0007 & 2.9567 & 0.0050 \\
AAR(-4) & -0.0015 & 272 & 340 & -1.4366 & 0.1422 & -1.5152 & 0.1266 \\
AAR(-3) & -0.0004 & 299 & 313 & -0.4119 & 0.3665 & -0.3651 & 0.3732 \\
AAR(-2) & 0.0004 & 304 & 308 & 1.3277 & 0.1652 & 1.4072 & 0.1482 \\
AAR(-1) & 0.0001 & 290 & 322 & 0.4958 & 0.3528 & 0.4922 & 0.3534 \\
AAR(0) & 0.0006 & 305 & 307 & 1.7168 & 0.0914 & 1.6104 & 0.1091 \\
AAR(1) & -0.0013 & 289 & 323 & -0.5098 & 0.3503 & -0.3787 & 0.3713 \\
AAR(2) & -0.0019 & 288 & 324 & -1.3736 & 0.1553 & -1.3618 & 0.1578 \\
AAR(3) & -0.0003 & 278 & 334 & 0.4645 & 0.3581 & 0.4263 & 0.3643 \\
AAR(4) & -0.0007 & 303 & 309 & -0.6044 & 0.3323 & -0.5951 & 0.3342 \\
AAR(5) & -0.0012 & 281 & 331 & -1.1741 & 0.2002 & -1.1220 & 0.2126 \\
AAR(6) & -0.0004 & 303 & 309 & -0.0960 & 0.3971 & -0.0903 & 0.3973 \\
AAR(7) & -0.0006 & 282 & 330 & -0.7891 & 0.2922 & -0.7349 & 0.3045 \\
AAR(8) & 0.0002 & 293 & 319 & 0.2371 & 0.3879 & 0.2491 & 0.3868 \\
AAR(9) & 0.0004 & 285 & 327 & 0.4438 & 0.3615 & 0.4394 & 0.3622 \\
AAR(10) & -0.0014 & 272 & 340 & -2.2215 & 0.0338 & -2.0577 & 0.0480 \\
\hline
\end{tabular}

Tablo 3'de olumlu ve şartlı denetim görüşü bildirilen firmaların hisse senetlerinin ortalama anormal getirilerinin tamamında (T) olay günü, olay gününün (T-8), (T-5), (T-2), (T-1) gün öncesi ve olay gününün $(T+8),(T+9)$ gün sonrası ortalama anormal getirilerinin pozitif olduğu görülmüştür. $(-10,+10)$ olay aralığında diğer günlerin ortalama anormal getirilerin tamamının negatif olduğu görülmektedir. Olay gününün 10 gün öncesi (T-10)'de istatistiksel anlamda 0,10 anlamlılık, 6 gün öncesi (T-6), 5 gün öncesi (T-5) ve 10 gün sonrası $(T+10)^{\prime}$ da ise istatistiksel anlamda 0,05 anlamlılık seviyesine sahip olduğu görülmektedir.

Olumlu ve şartlı denetim görüşü bildirilen firmaların olay günü on gün öncesi (-10) ve on gün sonrası $(+10)$ hisse senetleri ortalama anormal getirilerinin tamamının negatif ve pozitif yönlü dağılım grafiği Şekil 3'de raporlanmıştır.

Şekil 3: Olumlu ve Şartlı Denetim Görüşü (AAR) Anormal Ortalama Getiriler $(-10,+10)$

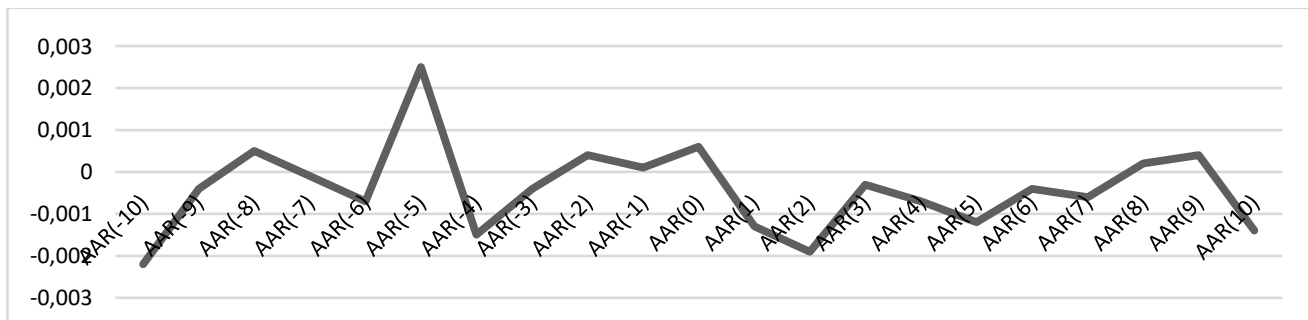

Şekil 3'de olumlu ve şartlı denetim görüşü bildirilen firmaların AAR $(-10,+10)$ olay aralığında hisse senetleri ortalama anormal getirilerinin tamamının negatif ve pozitif değerleri grafik üzerinde gösterilmiştir. Olumlu ve şartlı denetim görüşü bildirilen firmaların hisse senetlerinin ortalama anormal getirilerinin tamamında olay gününün (T-10) gün öncesi en düşük negatif ortalama anormal getiri elde ettiği görülmektedir. Olay gününün (T-5) gün öncesinde ise en yüksek pozitif ortalama anormal getirileri elde ettiği görülmektedir. 
Olumlu ve Şartlı denetim görüşü bildirilen firmaların olay günü öncesi (-10) ve sonrası (+10) hisse senedi kümülatif ortalama anormal getirilerinin tamamı Tablo 4'de raporlanmıştır.

Tablo 4: (CAAR) Kümülatif Anormal Ortalama Getiriler (-10, +10)

\begin{tabular}{lccc}
\hline & Tamamı & Olumlu & Şartlı \\
\hline \hline \multicolumn{1}{c}{ CAAR (-10, 10) } & -0.0084 & -0.0082 & -0.0088 \\
Pozitif Getiri Sayısı & 278 & 204 & 74 \\
Negatif Getiri Sayısı & 334 & 243 & 91 \\
Patell Z & -0.7708 & -0.7601 & -0.2335 \\
Olasılık & 0.2964 & 0.2988 & 0.3882 \\
StdCSect Z & -0.8144 & -0.8039 & -0.2296 \\
Olasılık & 0.2863 & 0.2888 & 0.3886 \\
\hline
\end{tabular}

Tablo 4'de $(-10,+10)$ olay aralığında pozitif getiri sayısının 278 , negatif getiri sayısının ise 334 olduğu görülmüştür. Pozitif getirilerin 204 tanesini olumlu denetim görüşü, 74 tanesini ise şartlı denetim görüşü oluşturmaktadır. Negatif getirilerin ise 243 tanesi olumlu denetim görüşü oluştururken, 91 tanesini ise şartlı denetim görüşü oluşturmuştur. Çalışmanın sonucuna göre ($10,+10)$ olay aralığında istatistiksel olarak anlamlı bir getiri elde edilmemiştir.

Sonuçlar kullanılan olay aralığının uzunluğuna duyarlı olabilmektedir. Bu yüzden emin olmak için alternatif olay aralıkları da test edilmiştir. Bağımsız denetim görüşünün hisse senedi getirilerine $(-10,+10)$ olay aralığında bir etkisinin olmadığı görüldükten sonra buna ek olarak ($5,+5)$ ve $(-1,+1)$ olay aralıklarının etkileri de araştırılmış ve Tablo 5 'de raporlanmıştır.

Tablo 5: (CAAR) Kümülatif Anormal Ortalama Getiriler $(-5,+5)$ ve $(-1,+1)$

\begin{tabular}{lccc}
\hline & Tamamı & Olumlu & Şartlı \\
\hline \hline \multicolumn{1}{c}{ CAAR (-5, 5) } & -0.0037 & -0.0026 & -0.0067 \\
Pozitif Getiri SayıSı & 305 & 229 & 76 \\
Negatif Getiri Sayısı & 307 & 218 & 89 \\
Patell Z & 0.6210 & 0.7263 & 0.0006 \\
Olasılık & 0.3290 & 0.3065 & 0.3989 \\
StdCSect Z & 0.6224 & 0.6883 & 0.0347 \\
Olasılık & 0.3287 & 0.3148 & 0.3987 \\
& -0.0007 & 0.0014 & -0.0062 \\
Pozitif Getiri SayıSı & 300 & 224 & 76 \\
Negatif Getiri SayıSı & 312 & 223 & 89 \\
Patell Z & 0.9831 & 1.7732 & -1.0251 \\
Olasılık & 0.2461 & $0.0828^{*}$ & 0.2359 \\
StdCSect Z & 0.8782 & 1.5246 & -1.0099 \\
Olasilık & 0.2713 & 0.1248 & 0.2396 \\
\hline
\end{tabular}

Tablo 5 incelendiğinde, $(-5,+5)$ olay aralığında pozitif getiri sayısının 305 , negatif getiri sayısının ise 307 olduğu görülmektedir. Pozitif getirilerin 229 tanesini olumlu denetim görüşü, 76 tanesini ise şartlı denetim görüşü oluşturmaktadır. Negatif getirilerin ise 218 tanesini olumlu denetim görüşü oluştururken, 89 tanesini ise şartlı denetim görüşü oluşturmuştur. $(-5,+5)$ olay aralığında da istatistiksel olarak anlamlı bir getiri elde edilmemiştir. $(-1,+1)$ olay aralığında pozitif getiri sayısı 300, negatif getiri sayısının ise 312 olduğu görülmüştür. Pozitif getirilerin 224 tanesini olumlu denetim görüşü, 76 tanesini ise şartlı denetim görüşü oluşturmaktadır. Negatif getirilerin ise 223 tanesini olumlu denetim görüşü oluştururken, 89 tanesini ise şartlı denetim görüşü oluşturmuştur. Çalışmanın $(-1,+1)$ olay aralığından elde edilen sonuçlara göre, olumlu denetim görüşü sonrası hisse senedi getirileri üzerinde 0,10 güven düzeyinde istatistiksel olarak anlamlı çıktığı görülmektedir.

Bu sonuçlara göre bağımsız denetim görüşünün hisse senedi getirileri üzerine etkisi (-10, $+10)$ ve $(-5,+5)$ olay aralığında istatistiksel olarak anlamlı değildir. $(-1,+1)$ olay aralığında ise, olumlu denetim görüşünün hisse senedi getirileri üzerinde kısa süreli de olsa anormal getiriye 
sebep olduğu ve bu sonucun $\% 10$ güven düzeyinde istatistiksel olarak anlamlı çıktığı görülmektedir.

\section{Sonuç}

Bağımsız denetimin amacı, finansal tablo kullanıcılarına, kamuya ve en önemlisi yatırımcılara güvenilir ve doğru bilgiler sunulmasını sağlamaktır. Yatırımcıların işletmenin mevcut durumu ve sürekliliği hakkında bilgiye ihtiyaç duyması ve bu bilginin güvenilir ve tarafsız hazırlanması bağımsız denetimin önemini ortaya koymaktadır.

Başarılı bir yatırımcının hisse senetlerine yatırım yaparken hisse senedi getirilerine etki eden faktörleri gözetmesi gerekir. Bu çalışmada, bağımsız denetim görüşlerin açıklandığı tarihin öncesi ve sonrasında hisse senedi getirilerine bir etkisinin olup olmadığı araştırılmıştır.

Araştırmadan elde edilen sonuçlara göre, yatırımcılar bağımsız denetim görüşü açıklama tarihinde ve $(-10,+10)$ olay aralı̆̆ında istatistiksel olarak anlamlı bir getiri elde edememişlerdir. Bu nedenle, bağımsız denetim görüşünün, yatırımcıların karar alma süreçlerinde bir etkisinin olmadığı sonucuna ulaşılmıştır. Bu sonuç, etkin piyasa hipotezi formlarından olan yarı-güçlü formda etkinliğin, çalışmanın kapsamındaki firmalar ve dönem kısıtıyla, BisT için geçerli olduğunu göstermektedir. Dolayısıyla bağımsız denetim görüşünün hisse senedi getirisine (-10, $+10)$ olay aralığında bir etkisinin olmaması $\mathrm{H}_{1}, \mathrm{H}_{1-a}$ ve $\mathrm{H}_{1-\mathrm{b}}$ hipotezlerini desteklememektedir. Bağımsız denetim görüşünün hisse senedi getirileri üzerinde herhangi bir etkisinin olmadığı sonucu, literatürdeki (Ameen, vd. , 1994; Martinez, vd. , 2004; Al-Thuneibat, vd. , 2008; Tahinakis, vd. , 2010; Moradi, vd. , 2011; Anvarkhatibi, vd. , 2012; Wickramasingha ve Nanayakkara, 2015; Ercan ve İ̧severoğlu, 2016) çalışmalarıyla paralellik göstermiştir.

Bağımsız denetim görüşünün hisse senedi getirisine $(-10,+10)$ olay aralığında etkisinin olmadığı gözlemlendikten sonra inceleme dönemine ek olarak $(-5,+5)$ ve $(-1,+1)$ olay aralıklarının etkisi de araştırılmıştır. Elde edilen sonuçlara göre, $(-5,+5)$ olay aralığında istatistiksel olarak anlamlı bir getiri elde edilmezken; $(-1,+1)$ olay aralığında olumlu denetim görüşünün hisse senedi getirileri üzerinde 0,10 güven düzeyinde istatistiksel olarak anlamlı bir etkisi olduğu görülmüştür. Bu sonuç, bağımsız denetim görüşünün kısa süreli de olsa anormal getirilere sebep olduğunu göstermektedir.

Bağımsız denetim görüşünün hisse senedi getirileri üzerine etkisinin araştırıldığı bu çalışmanın, Türkiye'de sınırlı sayıda bulunan çalışmalara ek olarak literatüre katkı sağlaması ve yatırımcılara, bağımsız denetim görüşlerinin karar alma süreçlerindeki değerlendirmeleri konusunda yol göstermesi beklenmektedir. 
Ağustos 2020, C. 15, S. 2

\section{Kaynaklar}

Al-Thuneibat, Ali A.; Khamees, Basheer Ahmad; Al-Fayoumi, Nedal A. (2008), "The Effect Of Qualified Auditors' Opinions On Share Prices: Evidence From Jordan", Managerial Auditing Journal, Vol. 23, No.1: 84-102.

Ameen, Elsie C.; Chan, Kam; Guffey, Daryl M. (1994), "Information Content of Qualified Audit Opinions for Over The Counter Firms" Journal of Business Finance and Accounting, Vol.21, No.7: 997-1011.

Anvarkhatibi, Saeid; Safashur, Mohammadreza; Mohammadi, Jamal (2012), "The Effect of Auditors Opinions on Shares Prices and Returns in Tehran Stock Exchange", Research Journal of Management Sciences, Vol.1, No:1: 23-27.

Ayanoğlu, Yıldız; Yılmaz, Abdulhamithan (2016), "TFRS'ye Uyumlu Finansal Tablolara Geçiş ve Oran Analizine Etkisi, Maden Sektörü Örneği" Gazi iktisat ve Işletme Dergisi, C.2, S.2: 41-66.

Aygören, Hakan; Uyar, Süleyman (2007), “istanbul Menkul Kıymetler Borsası’nda (IMKB) Denetim Görüşlerinin Hisse Senedi Getirileri Üzerine Etkisi", IMKB Dergisi, S.36: 31-52.

Boehmer, Ekkehart; Masumeci, Jim; Poulsen, Annette B. (1991), “Event-Study Methodology Under Conditions Of Event-Induced Variance", Journal of Financial Economics, Vol.30, No.2: 253-272.

Bozkurt, İbrahim; Öksüz, Sezer; Karakuş, Rıfat (2015), "Finansal Tablo İlanlarının Hisse Getirileri Üzerindeki Etkisi: BiST'de Ampirik Bir Uygulama", Maliye Finans Yazıları Dergisi, C.29, S.103: 113-140.

Brown, Stephen J.; Warner, Jerold B. (1980), "Measuring Security Price Performance”, Journal of Financial Economics, Vol.8, No.3: 205258.

Chen, Charles J.P.; Su, Xijia; Zhao, Ronald (2000), “An Emerging Market's Reaction to Initial Modified Audit Opinions: Evidence from The Shanghai Stock Exchan", Contemporary Accounting Research, Vol.17, No.3: 429-455.

Chen, Kevin C.W.; Church, Bryan K. (1996), "Going Concern Opinions and the Market's Reaction to Bankruptcy Filings", The Accounting Review, Vol.71, No.1: 117-128.

Dodd, Peter; Warner, Jerold B. (1983), "On Corporate Governance : A Study of Proxy Contests", Journal of Financial Economics, Vol.11, No.1-4: 401-438.

Ercan, Cuma; İşseveroğlu, Gülsün (2016), “Olumlu Denetçi Görüşünün Hisse Senedi Fiyatlarına Etkisi: Borsa İstanbul Örneği”, Akademik Bakış Dergisi, S.55:630-639.

Erol, Mikail; Aslan, Muhsin (2017), "Uluslararası Muhasebe ve Denetim Standartlarının Gelişmesi", Muhasebe ve Finans Tarihi Araştırmaları Dergisi, S.12: 55-86.

Fama, Eugene F. (1970), "Efficient Capital Markets A Review of Theory and Empirical Work", The Journal of Finance, Vol.25, No.2: 383417.

Firth, Michael (1978), “Qualified Audit Reports: Their Impact on Investment Decisions”, American Accounting Association, Vol.53, No.3: 642-650.

Fleak, Sandra K..; Wilson, Earl R. (1994), "The Incremental Information Content of The Going-Concern Audit Opinion", Journal of Accounting, Auditing and Finance, Vol.9, S.1: 149-169.

Hoti, Arbër H.; Ismajli, Hysen; Ahmeti, Skender; Dërmaku, Arben (2012), "Effects of Audit Opinion on Stock Prices: The Case of Croatia and Slovenia", Euro Economica, Vol.31, No.2: 75-87.

Kamu Gözetimi Muhasebe ve Denetim Standartları Kurumu, "Bağımsız Denetim Kuruluşları Listesi”, http://denkur.kgk.gov.tr/, (Erişim : 10.12.2018)

Kara, Suat (2015), "Denetim Görüşlerinin Hisse Senedi Anormal Getirileri Üzerine Etkisinin 2009-2014 Yılları Bazında Ölçümlenmesi”, Muhasebe ve Vergi Uygulamaları Dergisi, C.8, S.2: 137-152.

Kepekçi, Celal (2000), Bağımsız Denetim, Ankara: Siyasal Kitabevi.

Kolari, James W.; Pynnonen (2011), “Nonparametric Rank Tests For Event Studies”, Journal of Empirical Finance, Vol.18, No.5: 953-971.

Mackinlay, A.Craig (1997), "Event Studies in Economics and Finance", Journal of Economic Literature, Vol.35, No.1: 13-39.

Martinez, Maria Consuelo Pucheta; Martinez, Antonio Vico; Benau, Maria Antonia Garcia (2004), "Reactions of the Spanish Capital Market to Qualified Audit Reports", European Accounting Review, Vol.13, No.4: 689-711.

McWilliams, Abagail; Siegel, Donald (1997), "Event Studies in Management Research: Theoretical and Empirical Issues", The Academy of Management Journal, Vol.40, No.3: 626-657.

Mikkelson, Wayne H.; Partch, M.Megan (1986), "Valuation Effects of Security Offerings and The Issuance Process", Journal of Financial Economics, Vol.15, No.1-2: 31-60.

Moradi, Mehdi; Salehi, Mahdi; Rigi, Mehrollah; Mohsen Moeinizade (2011), "The Effect of Qualified Audit Report on Share Prices and Returns: Evidence of Iran" African Journal of Business Management, Vol.5, No.8: 3354-3360.

Patell , James M. (1976), "Corporate Forecasts of Earnings Per Share and Stock Price Behavior: Empirical Test", Journal of Accounting Research, Vol.14, No.2: 246-276.

Resmi Gazete, 1987, http://www.resmigazete.gov.tr/arsiv/19663.pdf, (Erişim: 25.12.2018).

Resmi Gazete, 2013, http://www.resmigazete.gov.tr/eskiler/2013/06/20130628-17.htm , (Erişim:25.12.2018).

Ryngaert, Michael; Netter, Jeffry (1990), "Shareholder Wealth Effects of The 1986 Ohio Antitakeover Law Revisited: Its Real Effects", Journal of Law, Economics and Organization, Vol.6, No.1: 253-262.

Tahinakis, Panayiotis; Mylonakis, John; Daskalopoulou, Evaggelia (2010), “An Appraisal of The Impact of Audit Qualifications on Firms' Stock Exchange Price Fluctuations", Journal Name Enterprise Risk Management, Vol.1, No.1: 86-92.

Ulusoy, Yasin (2007), Bağımsız Dış Denetim, Ankara: Seçkin Yayıncılık.

Vaziri, Alireza; Azadi, Kayhan (2017), "The Impact of Audit Reports on Financial Information Content", International Journal of Economics and Financial Issues, C.7, S.3: 304-308.

Wickramasingha, S.R.M.; Nanayakkara, K.G.M. (2015), “The External Auditor's Opinions and The Stakeholders' Purposes: An Empirical Analysis in Sri Lanka", Kelaniya Journal of Management, Vol.4, No.1: 31-49. 


\section{The Effects of Independent Audit Opinion on Stock Returns: Case of Borsa İstanbul}

In the independent audit, the financial statements are evaluated and the results obtained through the audit report are shared with the public. After the audit, the auditor gives four different opinions while explaining his results to the public. These types of views are; positive opinion, negative opinion, conditional opinion and refrain from expressing opinion. Audit reports and opinions released to the public after the audit may affect investors' decisions. Because these reports provide information to the investors about the companies. Investors can re-evaluate their assets with this information.

There are many factors that affect investors' investment decisions. These factors emerge in the form of rates obtained from the financial statement items, historical price data, and information about the firm, either publicly disclosed or not disclosed. In his study, Fama (1970) mentioned three types of effectiveness forms while expressing the Efficient Market Hypothesis, which includes explanations that all available information is fully reflected in stock prices. The first is effectiveness in weak form, which defends that no extra returns can be obtained from historical price data. The latter is called effectiveness in a semi-strong form and implies that no extra return can be obtained from both past prices and publicly disclosed information. The third is effectiveness in strong form. According to the effectiveness of the strong form, he argues that there will be no extra earnings from past prices, information disclosed to and disclosed to the public, and not disclosed to the public. Independent audit opinions are a criterion that can affect investors' investment decisions, as they are an important assessment of the company's financial statements.

The purpose of this study is to investigate the effect of independent audit opinions, which are considered as one of the criteria affecting investment decisions, on stock returns. For this purpose, in the research, the change in the return obtained by the investors in the days around the date of disclosure of audit opinion ( $t+10, t, t-10)$ in BIST was tested. The research problem has been tested with the help of the following hypotheses whether there is a change in stock returns before and after the independent audit opinion is announced (in the event range of $-10,+10$ ) and therefore whether stock returns are affected statistically.

$\mathrm{H}_{1}$ : Independent audit opinion has an impact on stock returns.

$\mathrm{H}_{1 \mathrm{a}}$ : Positive independent audit opinion has a positive effect on stock returns.

$\mathrm{H}_{1 b}$ : Conditional independent audit opinion has a negative effect on stock returns.

In the study, firms operating continuously between 2009 Q2 and 2018 Q1 are selected in BIST-ALL index. Among the 234 firms operating in the relevant period, the data of 18 firms publishing an independent audit report quarterly were used. It is seen that one of these 18 companies withdrew from BIST after 2015. Therefore, 612 audit opinions of 17 companies were used. 11 of these companies operate in the banking sector, 1 in real estate investment trusts and 5 in the manufacturing sector. Independent audit opinion data was obtained from Public Disclosure Platform (PDP). The stock end-of-day closing prices used to calculate stock returns are taken from BIST daily bulletins. A total of 21 days of stock closing price was compiled for each audit opinion, 10 days before, on the day of the event and 10 days after, and study data was created.

In this study, it is examined whether independent audit opinions have an effect on stock returns. This effect was investigated by applying the Event Study Method, Patell Z-Statistic and Standardized Cross-Sectional Test (StdCsect) tests. Due to the large number of observations ( $n>100$ ), the Patell- $Z$ test was preferred. The event study method is an econometric method used to measure the abnormal responses of the markets to the events, which allows to measure the impact on stock prices within a given event range. Event study is one of the methods frequently used in the literature to examine the effect of a particular event day on stock returns. In this method, firstly, the expected returns of the stock returns are calculated and the differences between the returns are analyzed. Fixed average returns model was used in the calculation of expected returns in the study. In the event study method, it is important to determine the event time and the event window. Long selection of the event window may decrease the power of the study statistically and may cause misinterpretation of the significance of the event. For this reason, the range of events accepted in the literature $(-10,+10)$ was chosen.

According to the results obtained from the research, investors were not able to obtain a statistically significant return on the date of independent audit opinion disclosure and the event range $(-10,+10)$. Therefore, it is concluded that the independent audit opinion has no effect on investors' decision-making processes. This result shows that the effectiveness of the semi-strong form, which is one of the effective market hypothesis forms, is valid for BIST, with the firms in the scope of the study and the period restriction. Therefore, the fact that the independent audit opinion has no effect on stock return $(-10,+10)$ in the event range does not support the hypotheses of the study. Then, in addition to the examination period, the effects of ($5,+5)$ and $(-1,+1)$ event intervals were also investigated. According to the results obtained, while $(-5,+5)$ no statistically significant returns were obtained in the event range; It was observed that the positive audit opinion $(-1,+1)$ had a statistically significant effect on the stock returns at the 0.10 confidence level. This result shows that the independent audit opinion causes abnormal returns, even for a short time. This study is expected to guide domestic and foreign investors in evaluating independent audit opinions in decision-making processes. 